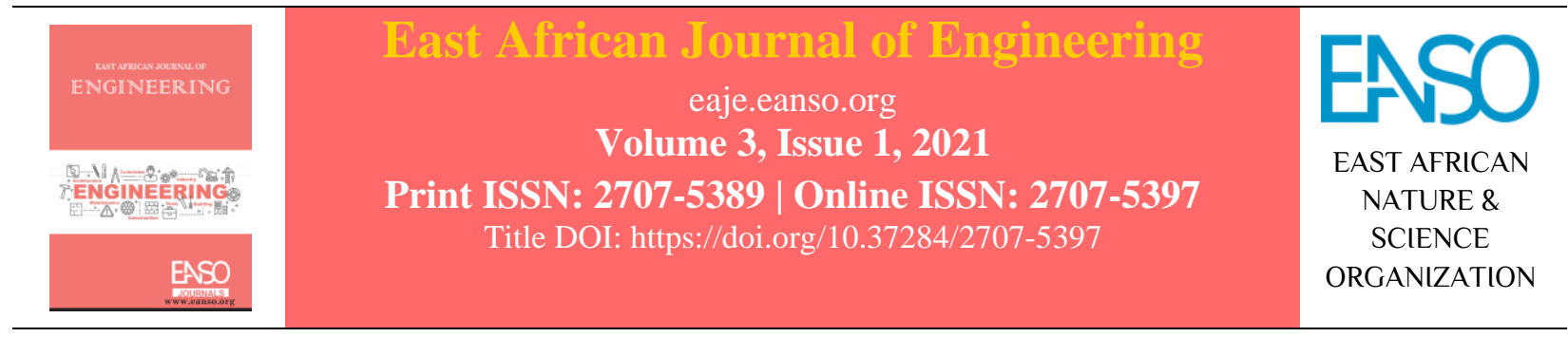

Original Article

\title{
A Study on Safety and Health Good Practices at Construction Sector in Jordan.
}

Sharaf Al-Deen Waleed AL-Smadi, MSc ${ }^{l^{*}}$, Assoc. Prof. Eris Elianddy Supeni, PhD ${ }^{l}$ \& Prof. Wong Shaw Voon, $P h D^{l}$

${ }^{1}$ Department of Mechanical and Manufacturing Engineering, Faculty of Engineering, Universiti Putra Malaysia, 43400 Serdang, Selangor, Malaysia, 21555.

* Author for Correspondence ORCID: 0000-0003-1442-0359; Email: sharafaldeensmadi1995@gmail.com.

Article DOI: https://doi.org/10.37284/eaje.3.1.399

\section{Publication Date: ABSTRACT}

02 September 2021 Safety and security are major factors that need to be prioritised by any party in the building and construction industry. Various regulations are

Keywords: required to be maintained by the authority regarding safety. The topic of study was the causes of the safety and security accidents in the

Civil Engineering, construction sector in Jordan. Dependent and independent variables Construction, aimed to understand the causes and factors responsible for accidents in the construction sector in Jordan. This research study is based on a quantitative research method where questionnaires were used to collect

Construction Safety in Jordan, Safety Accidents, data from the respondents. Demographic questions are made to Construction Management. categorise the respondents accordingly. The data was analysed using the SPSS tool. The research results helped to understand the study topic regarding safety accidents and good practices in the construction sector in Jordan.

\section{APA CITATION}

AL-Smadi, S. A. W., Supeni, E. E., \& Voon, W. S. (2021). A Study on Safety and Health Good Practices at Construction Sector in Jordan East African Journal of Engineering, 3(1), 57-71. https://doi.org/10.37284/eaje.3.1.399

\section{CHICAGO CITATION}

AL-Smadi, Sharaf Al-Deen Waleed, Eris Elianddy Supeni, \& Wong Shaw Voon. 2021. "A Study on Safety and Health Good Practices at Construction Sector in Jordan". East African Journal of Engineering 3 (1), 57-71. https://doi.org/10.37284/eaje.3.1.399.

\section{HARVARD CITATION}

AL-Smadi, S. A. W., Supeni, E. E., and Voon, W. S. (2021) "A Study on Safety and Health Good Practices at Construction Sector in Jordan”, East African Journal of Engineering, 3(1), pp. 57-71. doi: 10.37284/eaje.3.1.399.

\section{IEEE CITATION}

S. A. W., AL-Smadi., E. E Supeni., \& Voon, W. S "A Study on Safety and Health Good Practices at Construction Sector in Jordan," EAJE, vol. 3, no. 1, pp. 57-71, Sep. 2021.

57 | This work is licensed under a Creative Commons Attribution 4.0 International License. 


\section{MLA CITATION}

AL-Smadi, Sharaf Al-Deen Waleed, Eris Elianddy Supeni, \& Wong Shaw Voon. "A Study on Safety and Health Good Practices at Construction Sector in Jordan." East African Journal of Engineering, Vol. 3, no. 1, Sep. 2021, pp. 57-71, doi:10.37284/eaje.3.1.399.

\section{INTRODUCTION}

\section{General Overview}

The construction sector endangers the safety and health of workers when there is no proper implementation of efficient gadgets like PPE, safety measures at the site during the working process. Construction at public places increases the risk factors that endanger the safety of people even though they are not associated with the works. Therefore, the emergence of fatalities and the increasing rate of injuries is a major issue at construction sites. As a result of the growth, implementing sophisticated technology and industrial facilities at construction sites is a must-do for construction sites, as it will assist in improving the current state of the construction industry. Jordan's construction sector has the initiative to take a great response to the adoption of different technology and advancement in the existing construction structure.

A myriad of complications characterises the construction sector as it includes an expanded work range. This wide range holds different structural individuals and groups such as stakeholders, technical progress, and a greater number of employees and individual stakeholders. Inevitable disputes are quite often visible on the ground due to the nature of multi-faceted and the several parties' involvement. It is a time controlling and timeconsuming sector with the involvement of different parties within the work. While surveying the research process, the researcher came across different issues that lead to the emergence of the factors that hamper the environment of the construction workplace. It can be complicated with the involvement of different processes and collaborations, act upon the facilities of life with the over changing process and members within the ever-changing structure of the working process.

The concept of construction is broad and initiates capitals into different activities and processes that indulge preparation with different facilities, repairs, service, building development, and reconstruction. In Jordan, the construction sector has witnessed a rise in several negative impacts from 2015, 2017 and 2018. It is an important sector in this country as it contributes a large section to economic activities. The real estate market in this country has experienced a substantial and rapid rise in trading activity in the year 2013 (dspace.aeipro.com, 2020).

\section{Problem Statement}

The construction industry in Jordan is contemplated as an essential and supportive pillar of the Jordanian economy. Notwithstanding the passing of time, the country is trying to improve its structure in the construction business. Inadequate facilities and less availability of the health care facility are also played a significant role in backdropping the existing construction structures. Numerous failures are witnessed by the Jordan construction projects (Othman et al., 2020). It has also been found that problems of finance or economic backdrop can be considered a critical factor that triggers the failures in the projects in terms of delays. It can also be calculated that the low economic structure of the country also leads to a lack in the facilities of health care and professional treatments provided to the labour structure. Inefficient management structure in the construction business has given the rise of the problem that makes the most delay in a construction project. Management skill is the most influential factor that ensures progress in the entire process of work. This wide range holds different structural individuals and groups such as stakeholders, technical progress, and a greater number of 
employees and individual stakeholders (Zehro, 2020). Several faults can be recognised in Jordan's construction sector where it has been noticed that moving vehicles has caused accidents, having contact with the electrical discharges causes loss of life, exposure to the sun and hot or harmful substances etc., caused the maximum risk at construction sites. While serving with the research process, the researchers have come across different issues that lead to the emergence of the following factors that hamper the environment of the construction workplace. The economic backdrop and the traditional approach at work make the labourers face several accidents (Ashour \& Hassan, 2019). The existing professional health like immediate provision of first aid and health care facilities has not been mentioned or found as the construction is an immeasurable sphere with different aspects of labour.

\section{Aim and Objectives of Study}

The objective of this paper was to investigate the rate of safe accidents in the construction business of Jordan. In order to support research, the following research objectives were set to identify the causes of accidents in the construction sector and propose good safety and health practices.

\section{LITERATURE REVIEW}

\section{Construction industry at the Hashemite Kingdom of Jordan}

In the last ten years, the capital of Amman has doubled up its population, along with the construction sector, which rises to $2.8 \%$. Growing population in the Jordanian nation has raised the requirement of employment opportunities in the public sector. This builds employment in the business section. It has been noticed that the construction industry in the Jordanian sector has dramatically supported economic factors. This has been noticed the industries of construction are considered as an integral part of the Jordanian economy, and that too leads to the development of several constructional projects (Al Hayek, 2018). The infrastructural development in Jordan is an essential factor. Due to the increase in population and employment, the growing interest can be visualized in the public sector. Therefore, with the increasing involvement of the public in this particular sector increases the rate safety requirement and need for more preparative actions. Though it has been a dangerous industry, millions of accidents seem to occur in this sector all over the world. These safety accidents mainly caused damage and injuries to the workers and consequently brought the factors that cause a loss in consecutive years.

The increase in the diversity of information and the traditional operating and managing methods make safety management a challenging endeavour. Quality and safety management are essential factors in Jordan's construction industry due to the extended involvement of the people and the growing demand for development infrastructural growth that initiate the development and economic growth. 
Figure 1: Growth structure for Jordan's construction industry

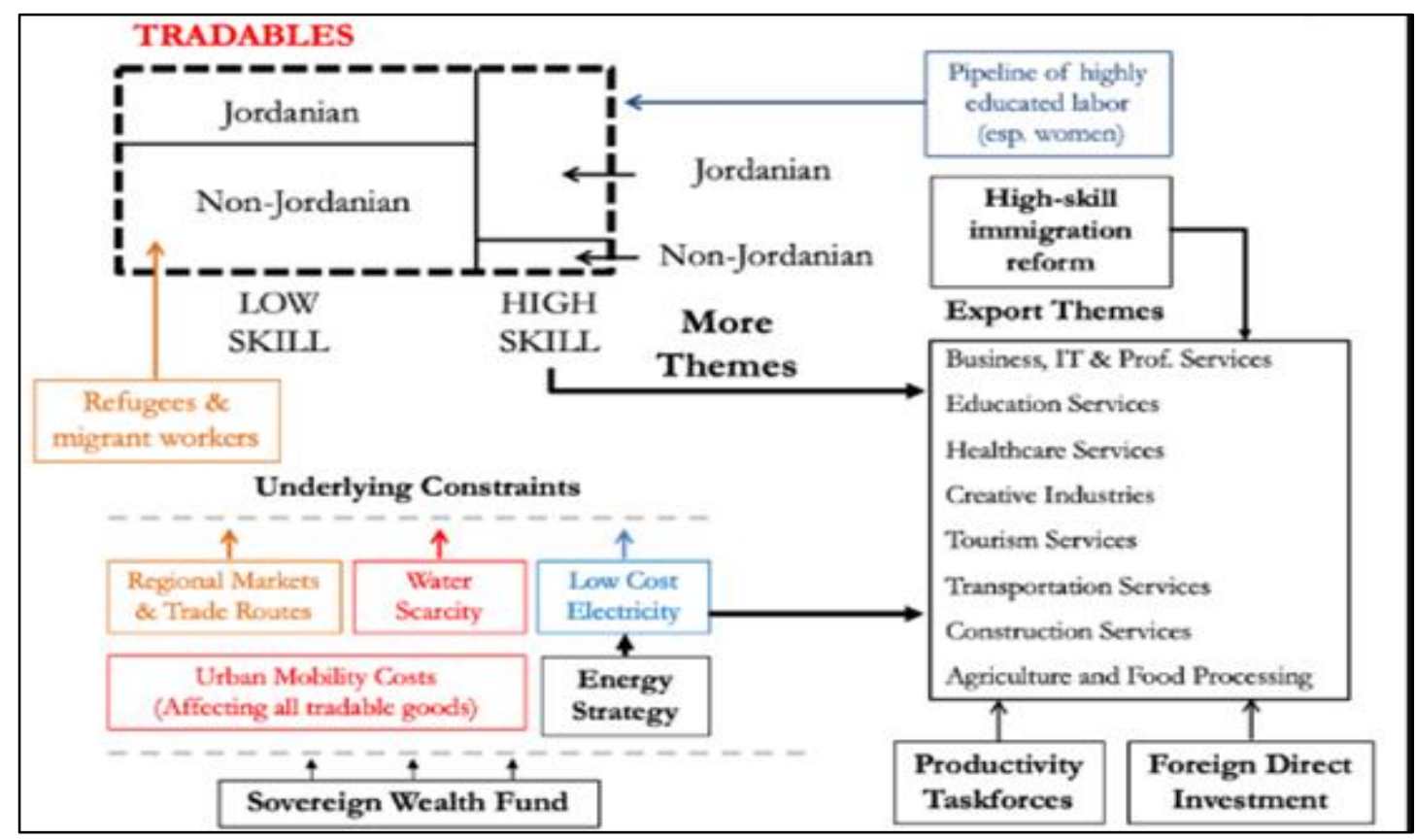

\section{Construction Safety of Jordan}

The construction industry is prone to different accidents and hazards, which may happen due to the lack of safety measures and professional health for the employee and related people. The presence of safety measures in construction organisations or project sites decreases the rate of accidents with time. Several factors are associated with safety measures and professional health. Mainly in Jordan where the increasing population has increased the demand for employment, initiating the requirement of safety for mitigation of the associated accidents and the risks of life loss and injuries at construction sites.

It has been mentioned in several journals that several fatalities ensue from the ground of safety measures. These safety accidents mainly result in damages and injuries to the workers and consequently other losses. There are several critical and noncritical challenges occurring at a regular rate in the construction sector of Jordan. Employees are the main human tools associated with the industry. This enables the country to act according to the growing development and advancement in this sphere. Every construction project includes human labour. Machines, associated members, raw materials, heavy vehicles and the most importantly the changeable weather are the general factors. Frequent weather changes can serve as the main factor that causes the most critical risks at the project sites. As the results of the loss of life, injury, delay and cancellation of the project has become one of the most critical aspects in the Jordanian industry. A safety hazard is a leading cause in the Jordan construction industries that led to accidents and injuries to the workers. Due to the financial and administrative problems construction industries often faced with management in change orders and in understanding the situations of the unknown sites, whatsoever creates the problems in setting the work routine and safety management.

\section{METHODOLOGY}

\section{Conceptual Framework}

The purpose of the research framework is to identify the main factors of safety accidents in the construction industry of Jordan under the

60 This work is licensed under a Creative Commons Attribution 4.0 International License. 
perceptions of clients, contractors, and consultants. The research primarily focused on investigating the relationship between the different factors such as factors of fall from a height, factors of slip and trips, factors of electrocutions, factors of getting caught or crushed and their various effects on the project safety under the perceptions of clients, contractors, and the consultants.

Figure 2: Conceptual framework of research

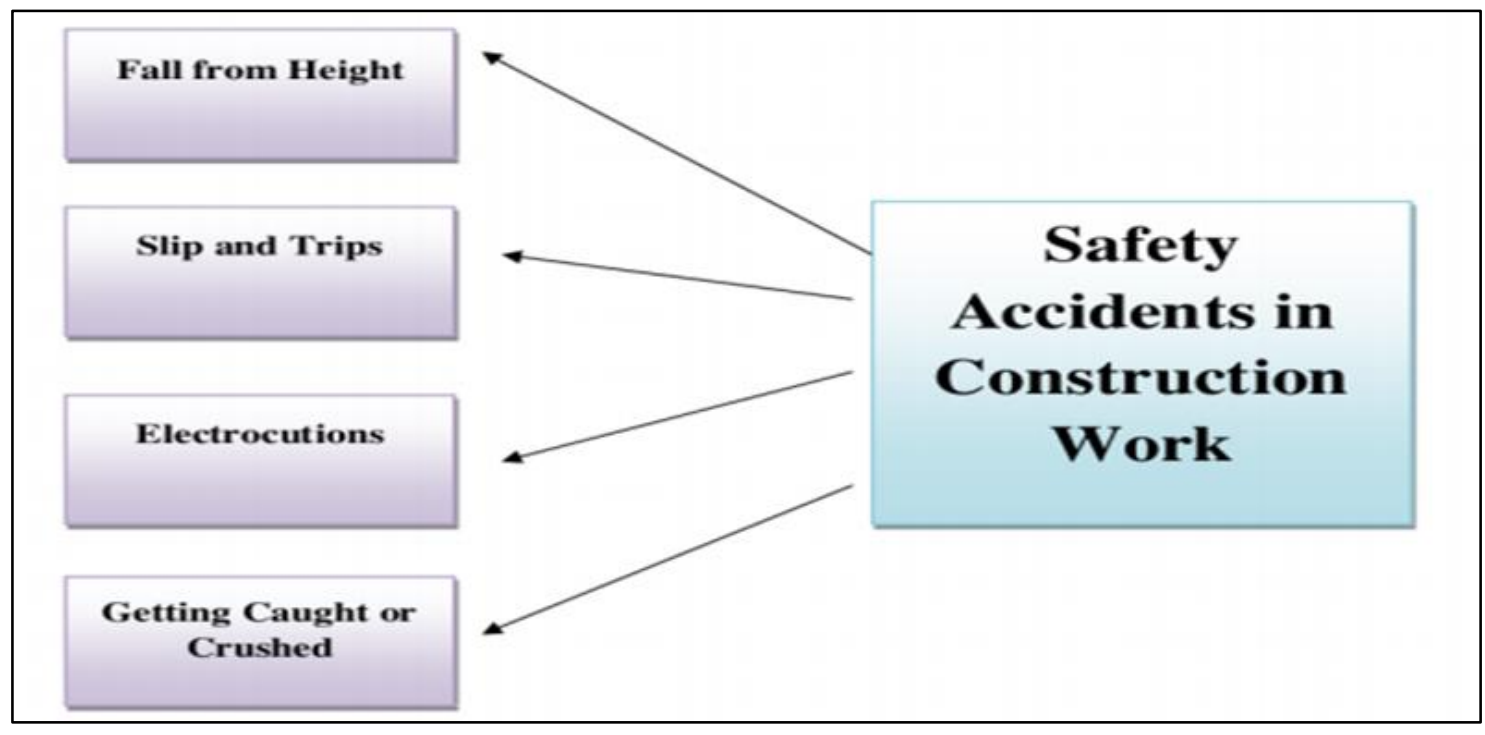

\section{Research Design}

Previous literature on construction accidents causes and their impact in various countries were studied. A questionnaire was designed comprising the causes and effects of construction accidents identified from the literature review. The target respondents were selected randomly from clients, contractors and consultants at the Hashemite Kingdom of Jordan.

The number of respondents (n) for this study was set at 100 respondents. However, 150 sets of questionnaires were distributed among respondents. This is to eliminate the risk of not-fully filled questionnaires and respondent turn down. Upon receiving the complete set of questionnaires, the score was analysed to understand the causes behind safety accidents.

\section{Questionnaire Design}

In order to achieve the objectives derived for this research, a questionnaire was designed to understand the viewpoint of different stakeholders related to safety accidents in the construction sector of Jordan. Part 1 comprised collected demographic information of the respondents, while part 2 with Likert-scale based questions. There are ten questions in the questionnaire of the research that will be used for collecting primary data, and the questionnaire is written in the English language for the access of everyone. The questionnaire is covered with an attached letter for the participant to ensure that the information is clear and understandable by the respondents. In that cover letter, the title and purpose of the research are stated clearly that will help the respondent to give an effective answer for the research work (Ranganathan, 2016). The questionnaire is consisted of 10 questions, from which two questions are related to the identity of the respondent, and the other 8 questions are related to the direct topic of the research work. These 8 questions include 4 factors of the safety accidents in the industry of constructions of Jordan such as factors of fall from a height, factors of slip and trips, factors of electrocutions, factors of getting caught or

61 This work is licensed under a Creative Commons Attribution 4.0 International License. 
crushed and their various effects towards the project safety under the perceptions of clients, contractors, and the consultants (Krosnick, 2018). The factors of fall from a height, factors of slip and trips, factors of electrocutions, and factors of getting caught or crushed are the independent variables where the dependent variable is project safety. As the entire safety measures will be depend on those mentioned in-dependable variables.

\section{Data Processing and Analysis}

The construction industry is a diverse industry with multiple key drivers who are involved in different activities and processes, and infrequent issues collaborate to bring out a single project. It can be better described as a constellation of various sectors and given with the complete building that in general components, types of equipment and the construction materials produced and delivered by other companies (Klumbyte, 2011). The primary discussion in this chapter was on the research framework, Development of the research hypotheses, research design, population and sample research, Sampling design, operational definitions and measurement of independent and dependent variables, data collection method, and data analysis techniques. The study of hypotheses investigated in this research is explained in this chapter of research methodology. The research work distributed to the respondents as per the target population that includes consultants, contractors, and customers in the industry of construction of Jordan. The participants are chosen rapidly from the northern area of Jordan. The methodology is adopted to answer the questions of the research that are discussed in this chapter. This is a further key analysis of the data and the results in the next chapter.

\section{RESULTS AND DISCUSSION}

\section{Demographic Analysis}

Demographic analysis is important to understand the nature of respondents in a descriptive study. The distributed questionnaires obtained demographic information of the respondents like gender, age, education background, position, experiences and company background in the construction industry of Irbid, Jordan. Table 1 represents the demographic profile of respondents and the company.

Table 1: Summary of Demographic Analysis

\begin{tabular}{llll}
\hline Item & & $\mathbf{N}$ & $\mathbf{\%}$ \\
\hline Gender & Male & 69 & 69 \\
& Female & 31 & 31 \\
\hline Highest education level & Primary Study & 1 & 1 \\
& Class 12th & 2 & 2 \\
& Bachelor degree & 47 & 47 \\
& Postgraduate & 50 & 50 \\
\hline Working experience & Less than 3 years & 64 & 64 \\
& 3-5 Years & 10 & 10 \\
& 5-10 Years & 10 & 10 \\
& More than 10 years & 16 & 16 \\
\hline Respondent position & Site Engineer & 50 & 50 \\
& Safety Engineer & 10 & 10 \\
& Labour & 6 & 6 \\
& other & 34 & 34 \\
\hline Citizenship & Jordanian & 88 & 88 \\
& Non-Jordanian & 9 & 9 \\
& Prefer not to say & 3 & 3 \\
\hline
\end{tabular}

$62 \mid$ This work is licensed under a Creative Commons Attribution 4.0 International License. 


\begin{tabular}{llll}
\hline Item & & $\mathbf{N}$ & $\mathbf{\%}$ \\
\hline Household income per month & Less than 300 JD & 26 & 26 \\
& (300-400) JD & 22 & 22 \\
& (400-500) JD & 19 & 19 \\
& Above 500 JD & 33 & 33 \\
\hline Age of respondent & $20-25$ Years & 43 & 43 \\
& 25-30 Years & 29 & 29 \\
& 30-35 Years & 16 & 16 \\
& 35 Years or above & 12 & 12 \\
\hline
\end{tabular}

Safety injuries related with the requirement of professional health in construction. As the construction sphere is considered as the domain of safety risks. Safety injuries in the Jordanian construction industry will be addressed in this study and their effect on the success of various projects. As a result, it has been regularly found that the Jordanian building industry has been exposed to safety accidents as well as a lack of professional health for employees employed in high-risk environments (Agresti, 2018). Here in this chapter, primary data analysis will be done considering the collected data. Questionnaires and a survey will be conducted to gather data from the selected participants. The participants will be (100) in number, and their participation will be judged on the basis of their reaction towards the set questions in the questionnaire.

Age as a demographic factor matters a lot in analysing the rate of safety accidents in the construction industry as age and experience matters a lot in the sphere of work. As this age factor also helps in determining the participation rate of the workers in construction business by using age distribution method. The reported age distribution shows that $43 \%$ of participants are between the ages of 20 and 25, who are often found to be involved in safety injuries due to carelessness.

Gender from the findings it has been observed that the participation of male workers in construction sector are more than that of the female workers in the construction industry. As it can be visible in the below stated graph where male participation is $69 \%$ and the participation rate of the females are less with
$32 \%$. As in the developing countries females are known to be related with their family life as majority are housewives and male workers due to lack of educational facilities participate or get employment in the construction industry.

Marital status from the findings it has been observed that most of the participants are unmarried that is around $67 \%$. Workers who are not married are likely to be more in percentage than that of the married participants. From this it can be stated that being married and being indulge with family responsibilities married employees avoid to deal with the dangers in construction projects. Therefore, increases participations of unmarried employees.

Educational qualification has been observed in the Table 1, that most of the workers are postgraduate and they also have BA degree but instead of that they also participated in the construction industry. It can be stated that construction industry highly influences employment structure for the new generation in Jordan countries.

Household income from the Figure 4.5 of household income, the graph is stated with different household income structure of the employees in the Jordanian construction industry. It is worth noting that the overall wage distribution of the three classes is almost identical. Although $33 \%$ of those surveyed have a household income of more than 500JD. As a result, it can be concluded that the construction industry is growing at a snail's pace. Employees' loss of interest and income can be attributed to a number of factors, including workplace safety accidents. 
The research contains some relevant hypothesis which states that may be safety accident and professional health are significantly present in the atmosphere of construction industry of Jordan. Impact of Jordan construction industry over the economy of Jordan has also been considered as a hypothesis. Thus, the idea providing employees with safety and health good practices at construction sites is significant. While incorporation of the safety and health good practices required to be made with the purpose of bringing deduction the safety accident.

\section{Finance Factor}

Financial factors greatly influence the overall construction projects. Therefore, here in this research, safety measures and health professionals are the major $\mathrm{g}$ factors on which the entire process has been focused (Assbeihat, 2015). Jordan's building sector has been found to have a poor occupational health record in this respect, having suffered financial and human casualties as a result of insufficient safety systems. Several surveys have shown that the protection of health facilities for laborers in Jordan has a poor structure in both quantity and quality instead of other countries' presence. Sometimes, the lack of several safety measures and different safety measures has impacted several high building constructions (Erogul \& Alyami, 2017). Getting caught or crushed is such a common phenomenon that occurs due to lack of safety measures at site and safety policy, improper budget planning and lack of awareness among labours. This is due to a shortage of building materials such as ladders, trucks, and machinery secured to the body, causing workers to get caught, smashed, and compressed between various obstacles at building sites (Huebschman et al. 2003). The two serious allegations that apply to these kinds of situations are "unguarded machines" and "construction equipment rollovers."

Figure 3: Labour awareness to risk factors impact project development

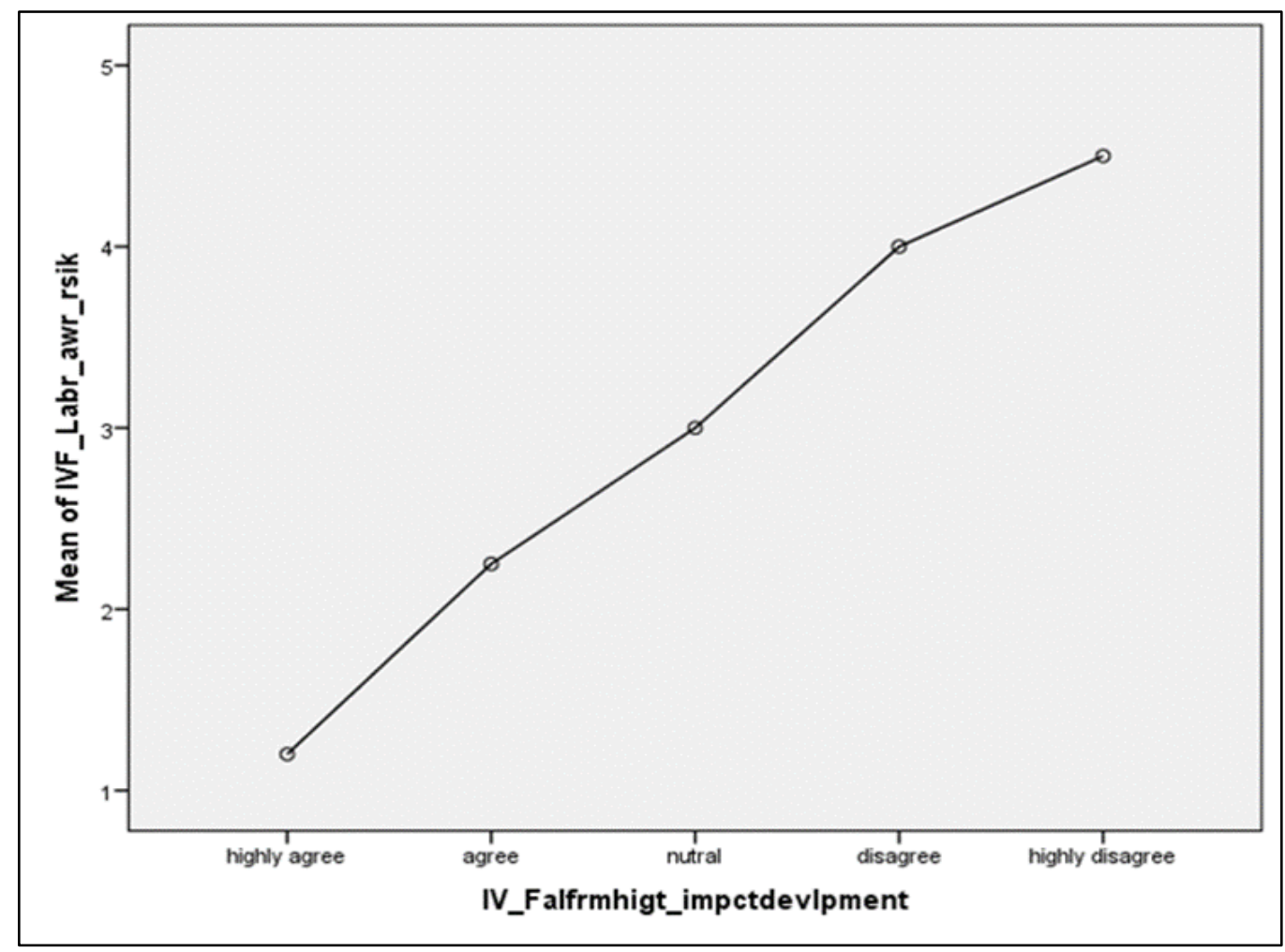

64 | This work is licensed under a Creative Commons Attribution 4.0 International License. 
Figure 3 illustrates the graph is indicating the labour should be aware of the possible risk in the construction industry as that will bring development in the entire process of any construction project. Making labour aware of their safety will make and keep them safe at any risky job (Abedelnoor, 2019). At the same time, participation of the labour will be constant, and that will enable the overall project to finish on time. This factor also influences budgetary issues that mitigate the financial crisis, making the entire process finish on time.

\section{Planning factor}

Construction scheduling boosts productivity, while efficient materials management and resource

\section{Figure 4: Application of safety tools and risk register in construction project}

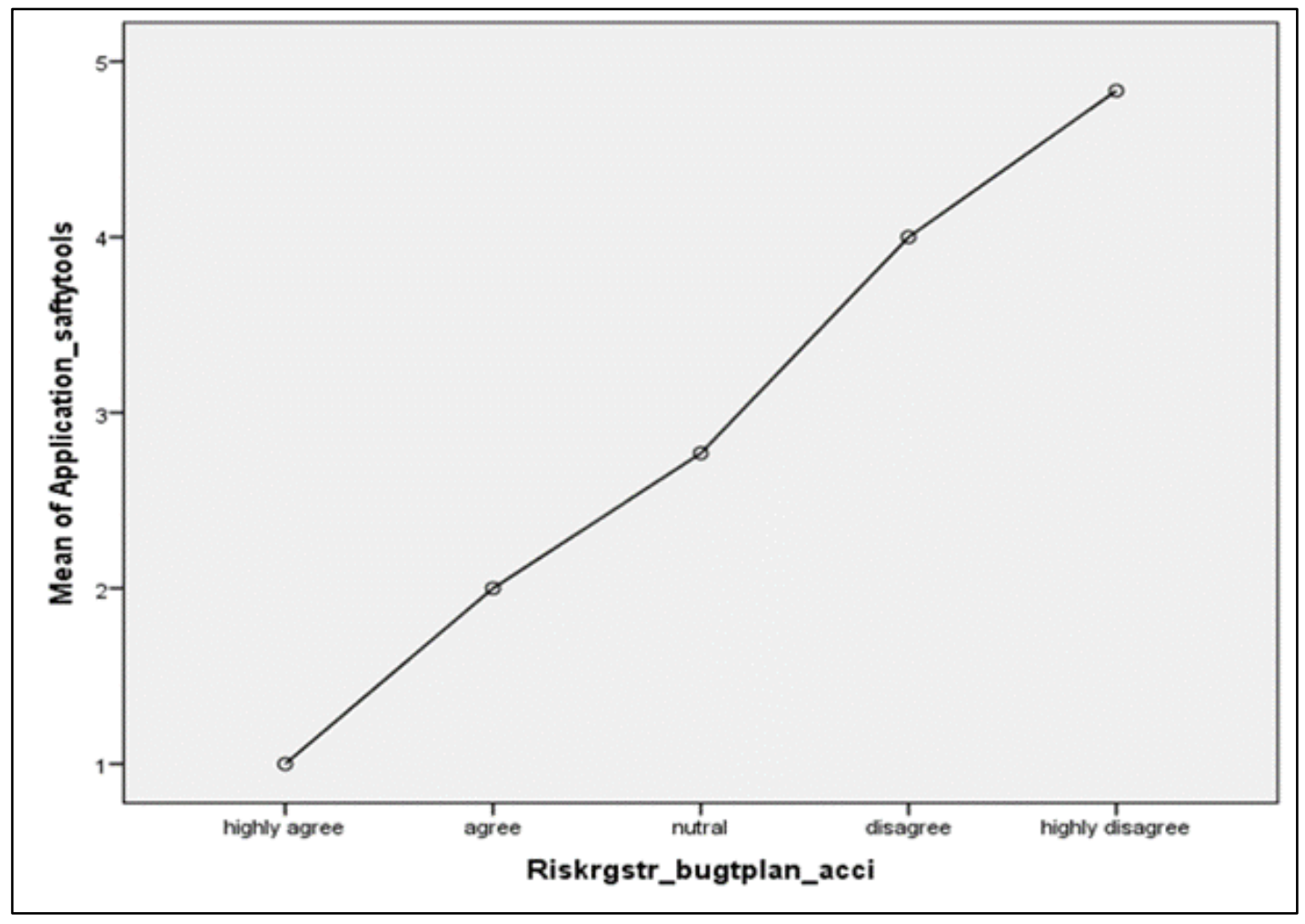

Figure 4 shows the graph the application of safety tools and risk register in construction project in which the relationship between the implementation of different safety tools and how it also influences the factors of implementing a risk register has been allocation cut costs and end up saving time. Project execution controls boost a team's ability to complete a project on deadline and under budget restrictions (Alhajeri, 2011). Thus, in this research, the researcher's main focus is on the causes that influence the safety accidents and presence of professional health in the sector of construction in Jordan. This research also focused on the influence that the above causes have on the progress of the work of the entire project (Alnsour, 2019). Thus, in the planning process of any construction project in Jordan must ensure implementation as well as the presence of different safety measures and professional health that will initiate mitigation of the accidents that are vividly spectacular in the construction industry. 
Several flaws have been identified in Jordan's architecture, where this has been observed that moving vehicles have caused collisions, that coming into contact with electrical discharges causes death, and so on (Zaid Alkilani, Jupp \& Sawhney, 2013). At construction sites, proximity to the sun, hot or hazardous liquids, and other conditions faced the greatest risk.

\section{External Factors}

Several external factors influence safety accidents, as well as the presence of safety and health good practices at construction sites in Jordan. It has been noticed that in spite of different external factors like rules and regulation, construction is also considered to be a risky zone for the health of the workers (Ozmec et al. 2015). Several risk factors generate due to lack of external factors like safety and health good practices recruitment, different safety schemes, safety and health insurance policy, limitation on working hours and introduction of a system of overtime charges and acceptance of different construction laws. The presence of all these external factors will ensure a better, safer environment for the labour and will encourage efficiency and development in the construction industry of the country of Jordan.

Figure 5: Different external factors influence safety accidents

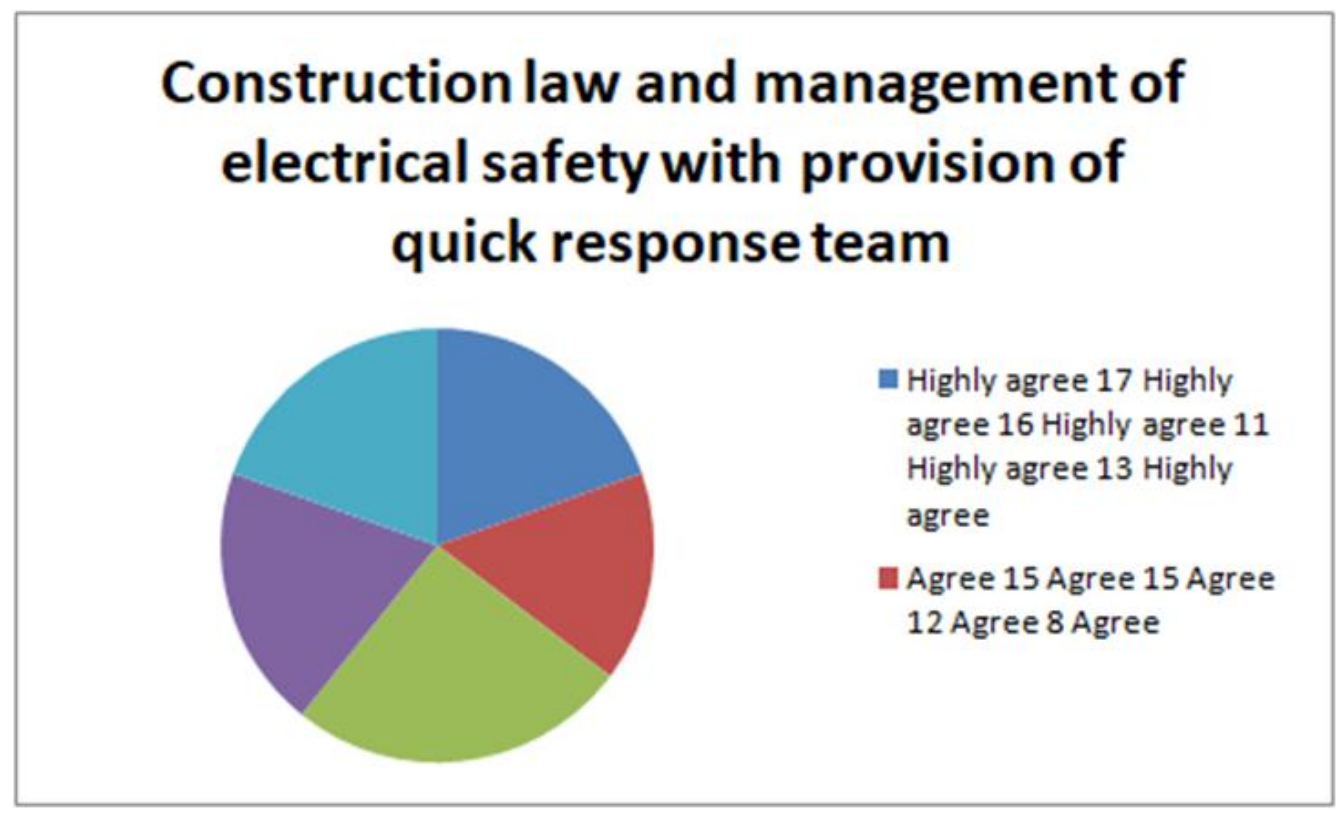

The promotion of different health and safety schemes in the ground of the construction industry in Jordan will ensure a safer working environment for the workers. More employment aspects will be encouraged in these sectors, and thus increase in the employment opportunity will initially influence growth and development. Thus, it has also been noticed that development will encourage advanced means of safety to the laborers. This will initiate the mitigation of safety accidents in working sites (Daoud, 2017, December). Trained workers will be scheduled and hired at building sites, allowing the job to be finished efficiently, and they will have adequate and appropriate knowledge of labour welfare standards and risk factors. To maintain a secure climate, building laborers' safety and health insurance plans should be updated in light of recent events in the t method. Labour wills and motivations will be bolstered by shortened operating hours and the imposition of overtime costs for labour effort (Montgomery, Peck \& Vining, 2021). Construction law and electrical safety control and the 
involvement of a rapid reaction team would guarantee professional well-being on the worksites. As can be seen in the referred pie map, 17 respondents strongly agreed on the application or presence of construction law and management in the area of electrical protection, as well as the presence of an appropriate and committed rapid response team. The respondent's answers to the presence of different variables for reducing have been 16, 13, and 11 , respectively.

\section{Descriptive Statistic}

Table 2: Descriptive Statistic of Demographic Data

\begin{tabular}{lll}
\hline & Mean & Std. Deviation \\
\hline Age & 2.39 & 1.133 \\
Gender & 1.35 & .483 \\
Marital status & 2.08 & .845 \\
Education & 2.37 & .824 \\
Ethnicity & 3.16 & 1.046 \\
Household income & 2.25 & 1.055 \\
\hline
\end{tabular}

The Descriptive Statistics of various demographic variables such as age, gender, marital status, education level, race, and the respondent's total household income are presented in Table 2. The mean age value is (2.39) $(\mathrm{SD}=1.133)$. The education level of the respondent holds the STD. The standard deviation is 0.824 , and the marital status factor is 0.845 . As a result, the standard deviation values of race and household income are much higher (1.046 and 1.055, respectively) than those of gender, marital status, and education. Education level can also greatly influence the level of understanding among the team members in the construction sites projects. Lower the education level will lower the outside knowledge of the workers, and thus they will not be able to have ideas regarding different labour safety acts and policies that can help mitigate their life risks at construction sites. Thus, it has been found that a lack of safety precautions suggests a lack of adequate and efficient labour safety preparation. Several defects in Jordan's construction have been uncovered, including incidents when moving cars have crashed. In this context, implementing different safety tools and promoting various health and safety schemes in Jordan's building sector would provide workers with a better working climate. More job facets will be promoted in these areas, and thus an increase in employment opportunities will initially affect growth and development.

Table 3: One-Way ANOVA

\begin{tabular}{lllllll}
\hline & & Sum of Squares & df & Mean Square & F & Sig. \\
\hline IVF_Labr_awr_rsik & Between Groups & 69.507 & 4 & 17.377 & 120.200 & .000 \\
& Within Groups & 6.650 & 46 & .145 & & \\
& Total & 76.157 & 50 & & & \\
\hline IVF_Rcrut_profsnl & Between Groups & 75.439 & 4 & 18.860 & 139.739 & .000 \\
& Within Groups & 6.208 & 46 & .135 & & \\
& Total & 81.647 & 50 & & & \\
\hline
\end{tabular}

According to Table 3, the discrepancy between the two factors, "labour perception of future risks" and "recruitment of skilled labours", tends to have a successful result in this condensed research. In this case, the Sig. Value for the variables turned out to be 0.000 . As a result, the difference within and within the groups of both variables may be inferred to be negligible (Bai et al., 2017). Thus, the requirement of both the factors in the construction industry is important for bringing safety measures

$67 \mid$ This work is licensed under a Creative Commons Attribution 4.0 International License. 
for eliminating the factors of accidents in Jordan's construction industry.

It has been concluded from the above data analysis section that job structure is a crucial factor for employment potential along with the rate of employment can be measured using this analysis. The Jordanian building industry has been exposed to safety accidents as well as a lack of professional health for employees employed in high-risk environments. Consequently, a new aspect of employment or a review of the current working arrangement of firms engaged in the building industry would be provided. As a result, as the public's interest in this industry grows, so does the rate of safety requirements and the need for more proactive measures. The promotion of various health and safety schemes in the building sector in Jordan would provide workers with a better working climate. In these areas, more job facets will be promoted, and thus an increase in employment opportunities will initially affect growth and development. Even though it has long been a risky industry, millions of incidents continue to occur considering the presence of advanced means of technology and safety instruments at construction will ensure a safer working environment. Recruitment of professional laborers from our professional bodies at working sites will enable us to have proper means of safety. This is due to a shortage of building materials such as ladders, trucks, and machinery secured to the body, causing workers to get caught, smashed, and compressed between various obstacles at building sites.

In these industries, more job dimensions will be promoted, and thus an increase in employment opportunities will initially affect growth and development. The dependent variable is promoting the health safety scheme, where the constant values are the safe work environment and the recruitment of professional employees. As a result, it has been noted that progress would promote advanced means of protection for laborers, thus initiating the prevention of workplace safety injuries (Ambigai \&
Prabhu, 2019). At construction sites, skilled employees would be scheduled and employed, enabling the job to be done quickly and with sufficient and effective knowledge of labour safety requirements and risk factors. This shows that there is a need for promoting the health safety scheme that will help to establish a work environment of safety, and this will also need to hire the employees that are professional staff.

The promotion of various health and safety schemes in the construction industry in Jordan would provide workers with a safer working climate. In view of the recent incidents in the method of construction, building laborers' protection and health insurance policies should be revised to ensure a secure environment. Shorter working hours and the imposition of overtime costs for labour effort will strengthen labour and motivation. Construction law and electrical safety laws, as well as the participation of a rapid response team, will be helpful. Every year in this sector around the world.

\section{CONCLUSION}

It can be concluded from the above Section the objectives of the research have been achieved and helped the researcher to find out the impact of safety accidents in the construction industry of Jordan. Construction legislation and electrical safety monitoring and the provision of a rapid response team must be set up in accordance with the project's risks. Electrical engineers and structural engineers should be hired to consider the risks, as this would also make employers aware of the dangers. The construction industry is often regarded as a dangerous industry due to the regular occurrence of safety-related injuries that raise the risk of death. With the passage of time and in light of the current state of the building industry, a number of solutions were needed.

\section{Limitations of the Study}

Many limitations were noted in this research creating challenges in gathering information and 
analysis of the gathered information. Finding information through the means of different secondary sources becomes a hectic task. In this research, secondary analyses were used in order to justify the stated objective. Information has been gathered through different existing research papers as well as through the means of an online survey. In doing so, maintaining authenticity and having constant checks on the duplication of the data play some significant roles in carrying out the entire process of data accumulation (Touitou, Reinberg \& Touitou, 2017). Setting questionnaires is another significant aspect of primary data analysis where the questions are required to be set up to meet with the research perspectives. More the questions will $b$ be relatable, and appropriate more will be the accuracy maintained in the information. But sometimes, participants do not provide accurate information and maintain a balance between positive and negative feedback. While being traditional in approach as well as maintaining their job ethics, participants who were the selected employers of the construction projects had maintained some restrictions in providing with their actual experiments. They stated their statement with utmost reality cheek, but they did not understand the importance of lack of knowledge or they might not want to answer in case of some questions. Therefore, a pause in the provision of correct answers creates a gap in gathering reliable sources of information. Sometimes lack of participants' initiative becomes an issue in the path of the entire data collection process.

\section{Recommendations}

The construction industry is often regarded as a dangerous industry, and the regular occurrence of safety injuries raises the risk of death. With the passage of time and in light of the current state of the building industry, a number of solutions were needed. Using various methods, multiple recommendations can be made based on the outcome of the results and the study's conclusions. With the high-risk levels in the building industry, workers should be mindful of potential hazards on the job site, and current health insurance policies should be reviewed in light of the rising number of workers. Skilled labourers should be hired on building projects to better enforce safety regulations. To avoid fall and trip risks, the team supervisor must organise a rapid medical response team in an accident. It refers to the presence of an involved medical specialist team at every construction job site.

Service hours were reduced, and overtime costs were added to compensate for the labour commitment needed to be funded. Constant capability assessment is crucial for increasing job efficiency and reducing the risk of the more recent technical adaptations. Simultaneously, with proper instruction, successful preparation improves capabilities. Construction legislation and electrical safety monitoring and the provision of a rapid response team must be set up in accordance with the project's risks. Electrical engineers and structural engineers should be hired to consider the risks, as this would also make employers aware of the dangers. Internal communication between labour and project supervisors needed to be improved, as this revealed the source of the problem. Internal communication between labour and project supervisors needs to be improved, as these revealed potentially dangerous risks. Good maintenance and coordination between workers and supervisors' aids are in installing critical construction equipment on job sites. In light of the current situation and the rising number of workplace safety incidents, the labour safety policy should adhere to ILO (International Labour Organization) recommendations to ensure a stable project implementation strategy.

\section{ACKNOWLEDGEMENT}

I want to thank Allah for helping me to complete this research paper within the stipulated time. I would like to express my gratitude to Associate Professor Eris Elianddy Supeni and Professor Dr

69 | This work is licensed under a Creative Commons Attribution 4.0 International License. 
Wong Shaw Voon who provided cooperation, insightful support and suggestions to improve this work.

\section{REFERENCES}

Abedelnoor, Y. N. Y. (2019). Site Safety Management for the Implementation of Construction Projects in Amman-Jordan. (Doctoral dissertation, Isra University).

Al Hayek, M. A. (2018). The Relationship Between Sales Revenue and Net Profit with Net Cash Flows from Operating Activities in Jordanian Industrial Joint Stock Companies. International Journal of Academic Research in Accounting, Finance and Management Sciences, 8(3), 149162.Retrieved

Alhajeri, M. (2011). Health and Safety in the Construction Industry: Challenges and Solutions in the UAE (Doctoral dissertation, Coventry University).

Ashour, A., \& Hassan, Z. (2019). The Role of the Work Environment on the Safety Performance and Safety Management Practices: Its Influence on the Attitudes of Nurses in the Jordanian Hospitals. American Journal of Applied Sciences, 16(11), 314-326.

Assbeihat, J. M. (2015). Construction Safety in Jordan-Conditions and Obstacles. Management, 4(3),193203.

Bai, L., Wang, H., Shi, C., Du, Q., \& Li, Y. (2017). Assessment of SIP buildings for sustainable development in rural China using AHP-grey correlation analysis. International journal of environmental research and public health, 14(11), 1292.

Daoud, J. I. (2017, December). Multicollinearity and regression analysis. In Journal of Physics: Conference Series, 949 (1), p. 012009). IOP Publishing.
Dspace.aeipro.com. (2020). Analysis of the jordanian construction sector. xmlui/bitstream/handle Retrieved From: http://dspace.aeipro.com/xmlui/bitstream/handl e/123456789/2438/AT02-

005_20.pdf?sequence $=1 \&$ isAllowed=y\#: :text $=$ The $\% 20$ construction $\% 20$ sector $\% 20$ in $\% 20 \mathrm{Jord}$ an, accounted $\% 20$ the $\% 205 \% 25 \% 20 \mathrm{in} \% 202018$. [Retrieved on: 03:03:2021]

Erogul, M. S., \& Alyami, M. M. (2017). Construction site safety in small construction companies in Saudi Arabia. International Journal of Management Practice, 10(4), 406421.

Hamid, A. R. A., \& Abd Majid, M. Z. (2006, June). Construction Safety Benchmarking. In Proceedings of the International Conference In The Built Environment (Vol. 21).

Huebschman, C. R., Garcia, C., Bullock, D. M., \& Abraham, D. M. (2003). Construction work zonesafety. Retrievedfrom: https://docs.lib.pur due.edu/cgi/viewcontent.cgi?article=1514\&cont ext=jtrp [Retrieved on: 15.03.2021]

Khoshnava, S., Ahankoob, A., Preece, C., \& Rostami, R. (2012, December). Application of BIM in construction safety. In Management in Construction Research Association (MiCRA). Postgraduate Conference, University Teknologi Malaysia, Malaysia.

Klumbytè, E. (2011). Work safety system improvement in construction/Darbu saugos sistemos tobulinimas statyboje. MokslasLietuvos ateitis/Science-Future of Lithuania, 3(2), 26-29.

Krosnick, J. A. (2018). Questionnaire design. In The Palgrave handbook of survey research (pp. 439-455). Palgrave Macmillan, Cham

70 This work is licensed under a Creative Commons Attribution 4.0 International License. 
Montgomery, D. C., Peck, E. A., \& Vining, G. G. (2021). Introduction to linear regression analysis. John Wiley \& Sons

Ozmec, M. N., Karlsen, I. L., Kines, P., Andersen, L. P. S., \& Nielsen, K. J. (2015). Negotiating safety practice in small construction companies. Safety Science, 71, 275-281.

Othman, I., Kamil, M., Sunindijo, R. Y., Alnsour, M., \& Kineber, A. F. (2020, April). Critical success factors influencing construction safety program implementation in developing countries. Journal of Physics: Conference Series, 1529 (4), 042079).

Ranganathan, B. (2016). Safety Performance In Construction Industries. Good housekeeping, 50(5), 10.

Samarah, A., \& Bekr, G. A. (2016). Causes and effects of delay in public construction projects in Jordan. American Journal of Engineering Research, 5(5), 87-94;

Schabenberger, O., \& Gotway, C. A. (2017). Statistical methods for spatial data analysis: CRC press.

Sherratt, F. S. (2012). Constructing safety on Sites: an exploration of the social construction of safety on large UK construction sites (Doctoral dissertation, University of Bolton).

Touitou, Y., Reinberg, A., \& Touitou, D. (2017). Association between light at night, melatonin secretion, sleep deprivation, and the internal clock: Health impacts and mechanisms of circadian disruption. Life sciences, 173, 94-106.

Zaid Alkilani, S., Jupp, J., \& Sawhney, A. (2013). Issues of construction health and safety in developing countries: a case of Jordan. Australasian Journal of Construction Economics and Building, The, 13(3), 141-156.
Zehro, K. (2020). Identification, determine and control of health, safety, and environmental hazards associated with the construction projects: State-Of-The-Art. International Journal of Advanced Engineering, Sciences and Applications, 1(4), 7-12. 